\title{
Tight Reservoir Properties Derived by Nuclear Magnetic Resonance, Mercury Porosimetry and Computed Microtomography Laboratory Techniques. Case Study of Palaeozoic Clastic Rocks
}

\author{
Paulina I. KRAKOWSKA and Edyta PUSKARCZYK
}

Faculty of Geology Geophysics and Environmental Protection, Department of Geophysics, AGH University of Science and Technology, Kraków, Poland; e-mail: krakow@agh.edu.pl

\begin{abstract}
Results of the nuclear magnetic resonance (NMR) investigations, mercury porosimetry measurements (MP) and computed microtomography (micro-CT), applied to the tight Palaeozoic rocks from the depths lower than $3000 \mathrm{~m}$, were presented to estimate their reservoir potential. NMR signal analysis and interpretation were performed. Based on NMR driven models, permeability and Free Fluid Index were calculated for data sets divided into homogeneous clusters. Computerized mercury porosimetry results visualization and processing provided useful information, as the automatically determined Swanson parameter is correlated with petrophysical properties of rocks. Micro-CT enriched the image of porous space in qualitative and quantitative ways. Homogeneity of pore space structure was discussed using micro-CT approach. Integration of the results in the frame of reservoir parameters from standard laboratory methods and the modern ones resulted in the improvement of methodology for determining the old, deep-seated, hard sedimentary rocks reservoir potential.
\end{abstract}

Key words: palaeozoic sedimentary rocks, nuclear magnetic resonance, mercury porosimetry, computed microtomography. 


\section{INTRODUCTION}

Petrophysical properties of deep-seated, old rocks are now a new research target due to the recent increased interest in tight gas formations (Monk 2013, Czekański et al. 2012). Previously, Precambrian and Palaeozoic sedimentary rocks were the objects of scientific research regarding the analysis of the sedimentary basins and recognition of the lithosphere structure (Bakun-Czubarow 1984, Jaworowski and Mikołajewski 2007, Kotarba 2010). Methodology which has been applied so far for investigation of hydrocarbon-bearing formations was mainly focused on precise determination of water or hydrocarbon saturation by selection of the adequate geological and geophysical models, e.g., in the Polish part of the Carpathian Foredeep (Zorski 2009, Zorski et al. 2011).

Precambrian and Palaeozoic sedimentary rocks may be analyzed from the point of their reservoir properties in prospecting for hydrocarbons, table and geothermal waters, and for estimation of the rock utility to the $\mathrm{CO}_{2}$ storage (Kiersnowski et al. 2010, Semyrka et al. 2010, Such et al. 2010, Jarzyna et al. 2012, Xiao et al. 2014). Combination of laboratory measurements including nuclear magnetic resonance (NMR), mercury porosimetry (MP), and computed microtomography (micro-CT) leads to building up a detailed methodology in analyzing low porosity and low permeability rocks. Results obtained for selected rock samples are presented as an example of sophisticated approach to reservoir properties determination. An integration of the NMR and MP results using different permeability models (SDR, Coates, and clay-bound water) and fluid flow description was made. Information on pore space distribution was obtained from micro-CT experiments.

\section{MATERIAL}

Tight and hard rocks of the Cambrian, Silurian, Ordovician, Carboniferous, and Permian age, located at the depth range of 3007.2-4588.0 $\mathrm{m}$ in wells sited in the Polish territory were used as testing material (Table 1). Rock samples were selected from deep wells, complying with four conditions: (i) depth of the rock was greater than $3000 \mathrm{~m}$, (ii) rocks were of Precambrian or Palaeozoic age, (iii) lithology was represented by sandstones and claystones or carbonates (limestones and dolomites), and (iv) it was possible to probe the core sample of $0.10 \mathrm{~m}$ length and a quarter of core volume, which was cut at half of core's diameter (Fig. 1).

Deep wells were located in the north, south-east, and central Poland in selected geological units built of old rock formation (Fig. 2). Samples were initially interpreted in the aspect of lithology and age. Several well recognized methods of laboratory investigation of core samples were applied to determine bulk density and specific density, total porosity and absolute per- 
Table 1

Wells, depth, stratigraphy, and lithology of the studied rock samples

\begin{tabular}{|l|l|l|l|l|l|l|l|}
\hline No. & Well & Year & $\begin{array}{c}\text { Bottom } \\
\text { depth } \\
{[\mathrm{m}]}\end{array}$ & $\begin{array}{c}\text { Bottom } \\
\text { stratigraphy }\end{array}$ & $\begin{array}{c}\text { Sample } \\
\text { depth } \\
{[\mathrm{m}]}\end{array}$ & Lithology & Age \\
\hline 869 & H-IG1 & 1974 & 3520 & $\mathrm{Pt}$ & 3457 & sandstone & $\mathrm{Cm}$ \\
870 & O-IG1 & 1967 & 4298 & $\mathrm{Pt}$ & 4106 & sandstone & $\mathrm{Cm}$ \\
871 & P-IG1 & 1970 & 3930 & $\mathrm{Pt}$ & 3460 & sandstone & $\mathrm{Cm}$ \\
872 & S-IG1 & 1974 & 5120 & $\mathrm{Pt}$ & 3546 & claystone & $\mathrm{S}$ \\
873 & G-IG1 & 1972 & 3353.5 & $\mathrm{Cm}$ & 3012.3 & sandstone & $\mathrm{Cm}$ \\
874 & Ł-IG1 & 1975 & 5632 & $\mathrm{Cm}$ & 4588 & sandstone & $\mathrm{Cm}$ \\
876 & Si-IG1 & 1970 & 3010.3 & $\mathrm{Cm}$ & 3007.2 & sandstone & $\mathrm{Cm}$ \\
877 & T-IG5 & 1977 & 3850.5 & $\mathrm{Cm}$ & 3034 & sandstone & $\mathrm{O}$ \\
878 & Ż-IG1 & 1969 & 3276 & $\mathrm{Cm}$ & 3233 & sandstone & $\mathrm{Cm}$ \\
879 & L-IG1 & 1961 & 3310 & $\mathrm{O}$ & 3246.5 & claystone & $\mathrm{S}$ \\
889 & Br-1 & 1983 & 4065 & $\mathrm{C}$ & 3818 & sandstone & $\mathrm{C}$ \\
892 & C-IG2 & 1980 & 5020 & $\mathrm{P}$ & 4016 & sandstone & $\mathrm{P}$ \\
894 & Z-2 & 1976 & 4569.6 & $\mathrm{C}$ & 4498.6 & sandstone & $\mathrm{C}$ \\
896 & Op-PIG2 & 1991 & 3055 & $\mathrm{C}$ & 3045 & sandstone & $\mathrm{C}$ \\
\hline
\end{tabular}

Explanations: No. - sample number, Year - drilling year, Age - age of the rock sample, $\mathrm{Pt}$ - Proterozoic, $\mathrm{Cm}$ - Cambrian, O - Ordovician, S - Silurian, C - Carboniferous, $\mathrm{P}-$ Permian.

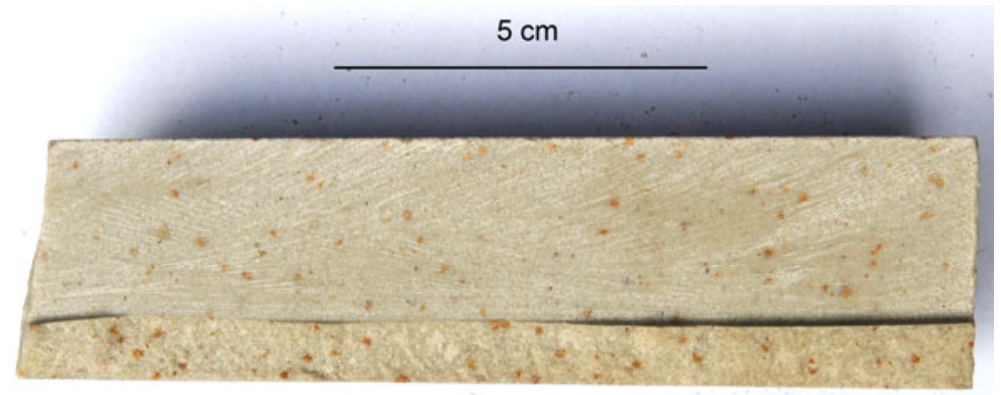

Fig. 1. Sandstone core sample No. 871, photo by M. Michna.

meability, $P$ - and $S$-wave velocity, etc., and special attention was paid to keep necessary preciseness and accuracy of measurements and determination of extreme values of measured parameters (Zalewska et al. 2011). The total porosity was determined on the basis of measurements carried out using two cooperative tools: pycnometer AccuPyc 1330 (specific density) and GeoPyc 


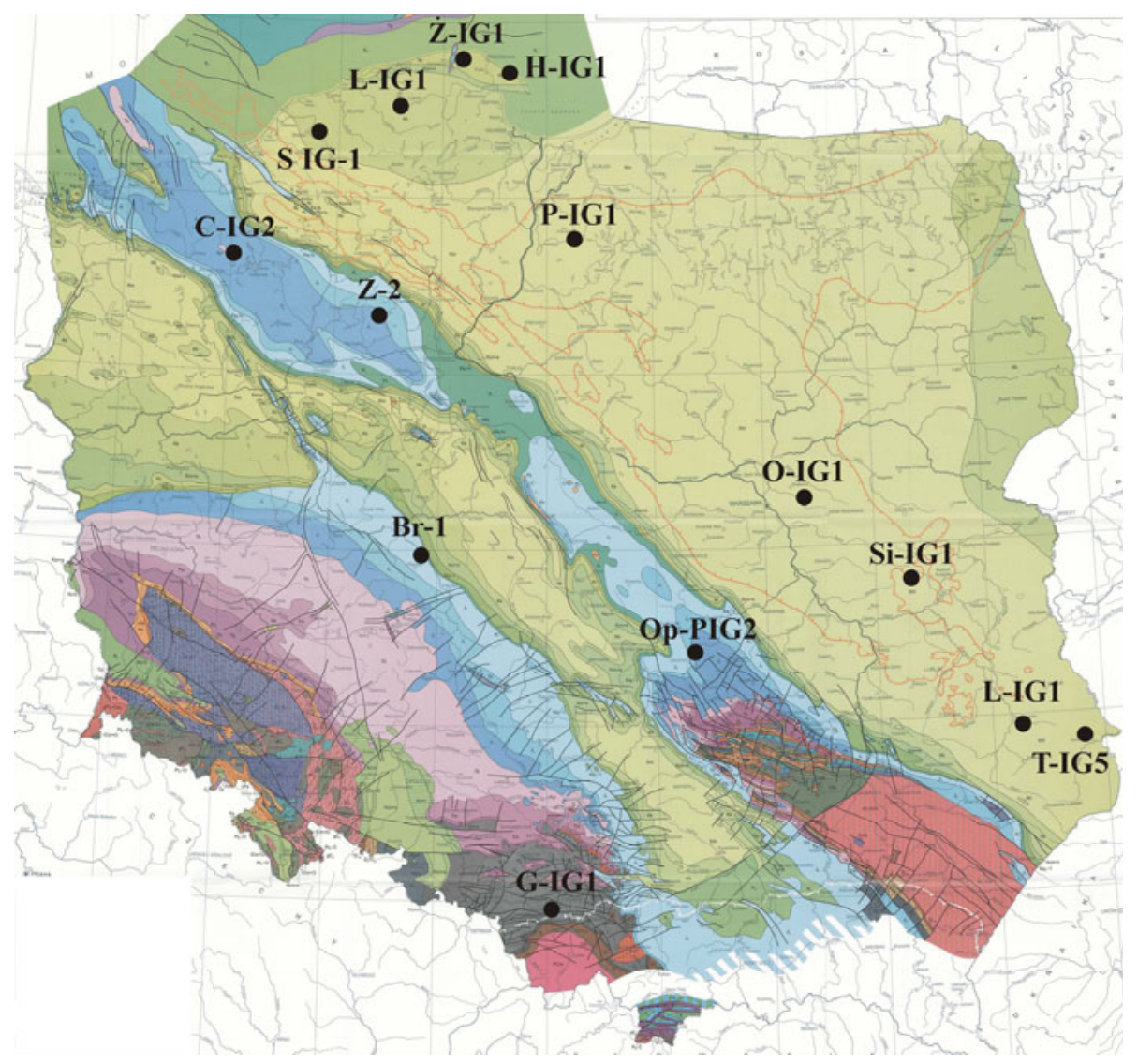

Fig. 2. Wells location on the geological map of Poland without Cenozoic deposits (Dadlez et al. 2000, modified); colours are related to stratigraphic units as follows: Proterozoic - red, Cambrian - dark green, Ordovician - dark violet, Silurian - dark blue, Devonian - brown, Carboniferous - grey, Permian - orange, Triassic - light violet, Jurassic - light blue, and Cretaceous - light green.

1360 (bulk density). An accuracy of porosity calculation was $\pm 1.5 \%$. Permeability was measured using Gas Permeameter (Temco Co.) with resolution not exceeding the $0.01 \mathrm{mD}$.

Petrophysical properties of the selected rock samples (12 sandstones and 2 claystones) are presented in Table 2 . Moderate variability of different parameters and rather small ranges of values of all presented variables are observed. For instance, bulk density of sandstones is in the range of 2.47$2.73 \times 10^{3} \mathrm{~kg} / \mathrm{m}^{3}$ and specific density varies in the range of 2.63$2.78 \times 10^{3} \mathrm{~kg} / \mathrm{m}^{3}$. Also, low total porosity $(0.8-8.47 \%)$ and very low permeability $(0.01-0.28 \mathrm{mD})$ are just going to show that special attention should be 
paid to these rocks and strong relationships between various parameters may form the way to characterize such rocks with indirect methods.

Table 2

Petrophysical properties of studied rock samples

\begin{tabular}{|c|c|c|c|c|c|c|c|c|c|}
\hline No. & $\begin{array}{c}\delta_{r} \times 10^{3} \\
{\left[\mathrm{~kg} / \mathrm{m}^{3}\right]}\end{array}$ & $\begin{array}{c}\delta_{b} \times 10^{3} \\
{\left[\mathrm{~kg} / \mathrm{m}^{3}\right]}\end{array}$ & $\begin{array}{c}\Phi \\
{[\%]}\end{array}$ & $\begin{array}{c}K \\
{[\mathrm{mD}]}\end{array}$ & $\begin{array}{c}V_{p} \\
{[\mathrm{~m} / \mathrm{s}]}\end{array}$ & $\begin{array}{c}V_{s} \\
{[\mathrm{~m} / \mathrm{s}]}\end{array}$ & $\begin{array}{c}V C \\
{[\mathrm{wt} \%]}\end{array}$ & $\begin{array}{c}\Phi \mu-\mathrm{CT} \\
{[\%]}\end{array}$ & $\begin{array}{c}\Phi \mathrm{mp} \\
{[\%]}\end{array}$ \\
\hline 869 & 2.65 & 2.57 & 3.18 & 0.05 & 5096 & 2591 & 6 & 1.7 & 0.83 \\
870 & 2.68 & 2.55 & 4.79 & 0.01 & 4813 & 2615 & 5 & 2.5 & 0.74 \\
871 & 2.63 & 2.61 & 0.80 & 0.01 & 4893 & 2729 & 0 & 0.5 & 0.29 \\
872 & 2.71 & 2.62 & 3.15 & 0.01 & 5054 & 2751 & 17 & 3.7 & 0.77 \\
873 & 2.71 & 2.66 & 1.76 & 0.02 & 4778 & 2772 & 11 & 1.6 & 0.37 \\
874 & 2.64 & 2.61 & 1.22 & 0.28 & 5141 & 2497 & 1 & 1.7 & 0.24 \\
876 & 2.69 & 2.57 & 4.41 & 0.06 & 4692 & 2260 & 15 & 2.6 & 0.18 \\
877 & 2.66 & 2.57 & 3.25 & 0.01 & 5008 & 2705 & 2 & 3.9 & 0.82 \\
878 & 2.70 & 2.47 & 8.47 & 0.01 & 4365 & 2454 & 16 & 2.1 & 1.21 \\
879 & 2.74 & 2.73 & 1.50 & 0.01 & 5549 & 3140 & 33 & 0.4 & 0.13 \\
889 & 2.78 & 2.69 & 3.36 & 0.07 & 4446 & 2522 & 41 & 0.9 & 0.17 \\
892 & 2.70 & 2.66 & 1.31 & 0.03 & 4445 & 2494 & 4 & 0.9 & 0.26 \\
894 & 2.67 & 2.6 & 2.46 & 0.01 & 5144 & 2647 & 3 & 1.3 & 4.43 \\
896 & 2.70 & 2.72 & 1.50 & 0.01 & 5350 & 2598 & 21 & 0.4 & 0.09 \\
\hline
\end{tabular}

Explanations: No. - sample number, $\delta_{r}-$ specific density, $\delta_{b}$ - bulk density, $\Phi$ - total porosity from laboratory measurements, $K$ - absolute permeability from laboratory measurements, $V p-P$-wave velocity, $V s-S$-wave velocity, $V C$ - clay minerals content from Roentgen analysis, $\Phi \mu$-CT - porosity from computed microtomography, $\Phi \mathrm{mp}$ - porosity from mercury porosimetry.

\section{METHODOLOGY}

New technologies in laboratory investigations on rock plugs together with well-known verifiable techniques were the basis of detailed low porosity and low permeability rock analysis. Computed microtomography, NMR spectroscopy and mercury measurement confirmed the ability of detailed rock samples investigations to improve the precision of reservoir properties determination.

\subsection{Nuclear magnetic resonance (NMR) measurements and interpreta- tion}

NMR technique applied in petrophysics and well-logging uses the effect of relaxation of protons in the hydrogen atoms in rock formation. Hydrogen oc- 
curs in rocks in the form of water or hydrocarbons contained in rock pores, water bound in clay minerals and hydrogen included in hydroxyl groups in these minerals. The basic parameters observed in relaxation examination are: proton signal amplitude, spin-lattice relaxation time $T_{1}$ and spin-spin relaxation time $T_{2}$ (Andrew 1969). These parameters are the source of detailed information about porosity (total and effective), irreducible water saturation and permeability of reservoir rocks, pore space structure and type of liquid filling rock pores (Coates et al. 1999). In the multiphase systems, e.g., rocks where media of diverse quality fill the complex rock pore space, the spinspin relaxation curve can be presented as a sum of components characterized by the relaxation time $T_{2}$. The continuous distribution of relaxation times is directly related to distribution of pore sizes in the examined rock sample. Individually selected $T_{2}$ cut-offs included into interpretation of NMR signals improve the determination of bound water volume and moveable media in rock formation (Liu et al. 2007).

NMR measurements were performed using NMR Maran7 equipped with permanent magnet generating $0.186 \mathrm{~T}$ intensity field. Frequency of hydrogen nuclei precession was equal to $7.9 \mathrm{MHz}$. Measurements were carried out in the temperature of $35^{\circ} \mathrm{C}$. Core samples $(0.04 \mathrm{~m}$ in length and $0.0254 \mathrm{~m}$ in diameter) were saturated with brine $(\mathrm{NaCl}$ mineralization $=50 \mathrm{~g} / \mathrm{l})$. Before each measurement series, a control measurement on the standard reference was done. Standard reference (porosity $=15 \%$ ) was saturated with brine (containing hydrogen and deuterium) of $\mathrm{NaCl}$ mineralization $=50 \mathrm{~g} / \mathrm{l}$. Spinspin relaxation times were measured with pulse methods using the CarrPurcell-Meiboom-Gill spin echo methodology.

Based on $T_{2}$ relaxation times distributions and standard $T_{2}$-cut-offs for clastic rocks ( 3 and $33 \mathrm{~ms}$ ), which are known from literature, e.g., Coates et al. (1999), Kenyon (1992), Kleinberg and Vinegarm (1996), Straley et al. (1997), total, effective and dynamic porosity was calculated. Cut-offs underline differences in porosity values related to water bound in clays or micropores $\left(T_{2}<3 \mathrm{~ms}\right)$, capillary water $\left(T_{2}>3 \mathrm{~ms}\right.$ and $\left.T_{2}<33 \mathrm{~ms}\right)$ and large pores filled with free water $\left(T_{2}>33 \mathrm{~ms}\right)$. Results of division into free, capillary and clay-bound water are shown in Table 3 and Fig. 3. Cumulated NMR signals normalized in relation to the maximum value were calculated and presented versus relaxation time $T_{2}$ to characterize the place of protons in the rock pore space (Fig. 4). Graphs of cumulated signals are used for qualitative description of the porous space in rocks. Three groups can be distinguished among the cumulated and normalized signals. Concave curves belong to the first group (e.g., 872, 876) corresponding to the rocks in which smaller pores or fractures dominate. The course of convex curves is typical for the rocks (e.g., 877) in which medium migration is performed in largediameter pores or fractures. The third group consists of graphs of nearly con- 


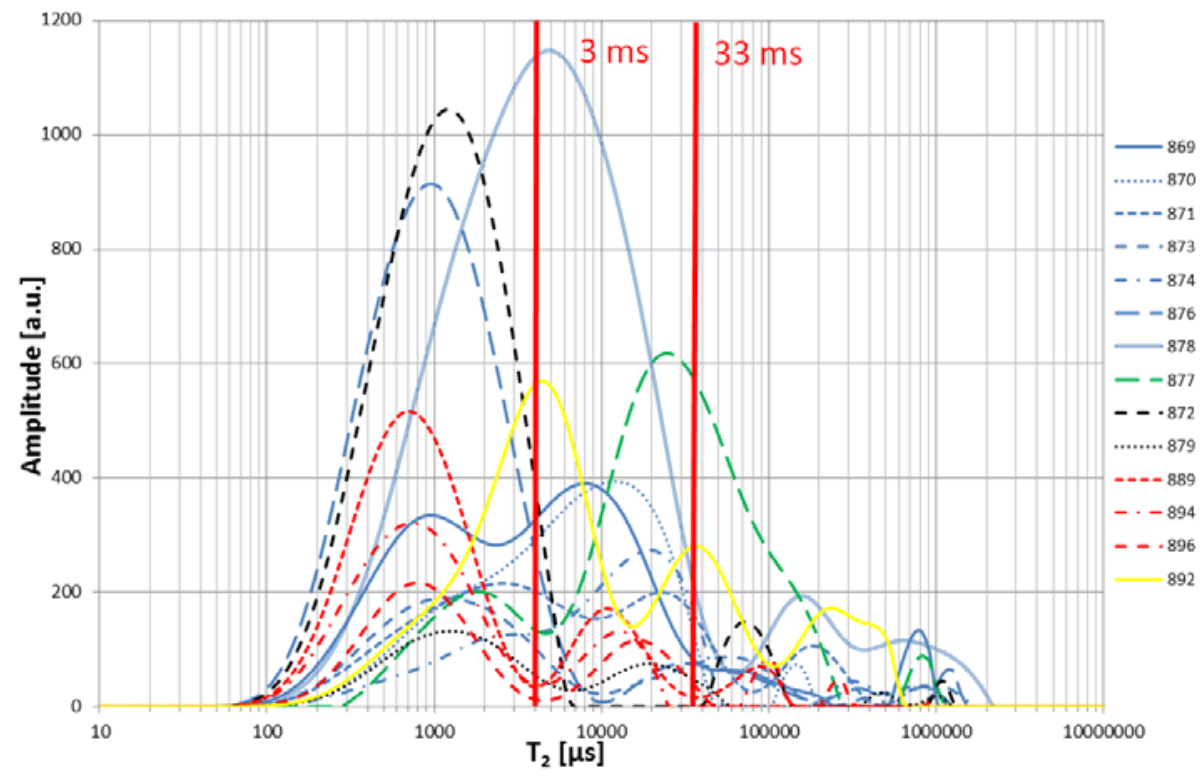

Fig. 3. $T_{2}$ distributions with division into clay-bound water, capillary water, and free fluid. Colours: Cambrian - blue, Ordovician - green, Silurian - black, Carboniferous - red, and Permian - yellow.

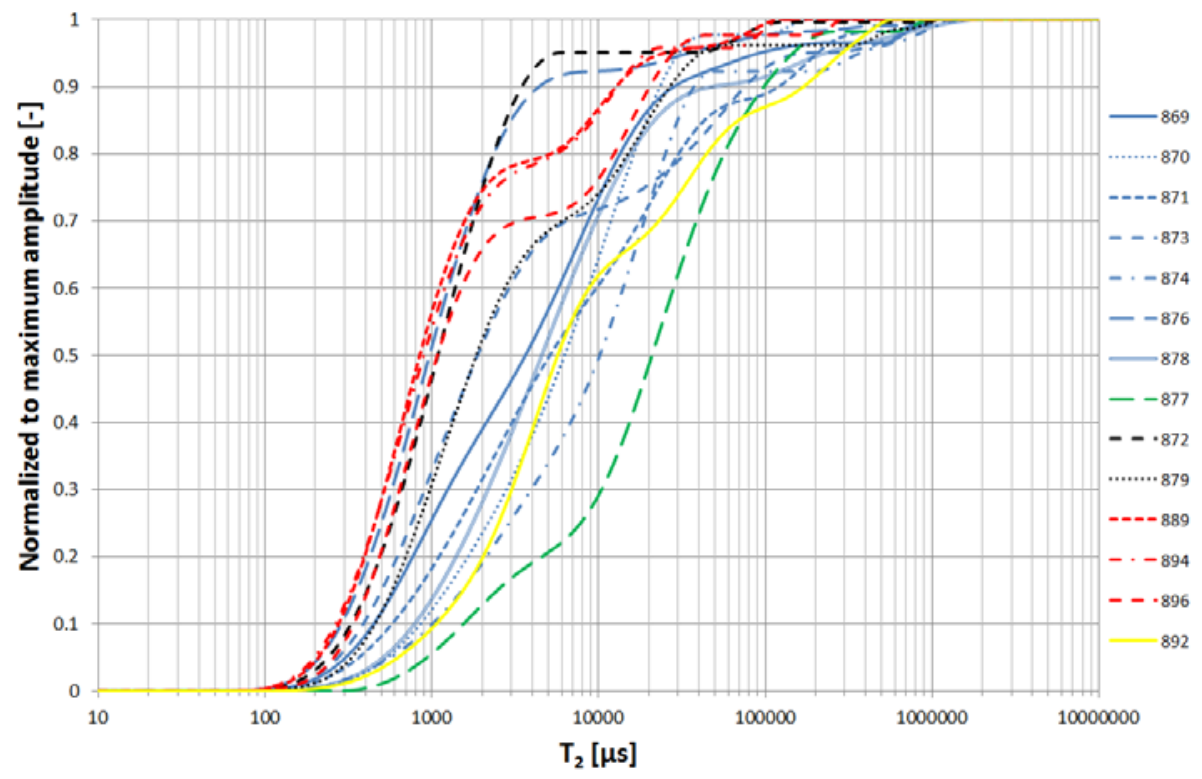

Fig. 4. Normalized cumulative NMR signal versus $T_{2}$ relaxation time. Colours as in Fig. 3. 
Results of the NMR interpretation using standard cut-offs

\begin{tabular}{|l|c|c|c|c|c|c|c|c|c|c|c|c|c|c|}
\hline No. & $\begin{array}{c}K p 1 \\
{[\%]}\end{array}$ & $\begin{array}{c}K p 2 \\
{[\%]}\end{array}$ & $\begin{array}{c}K p 3 \\
{[\%]}\end{array}$ & $\begin{array}{c}\Phi_{\mathrm{NMR}} \\
{[\%]}\end{array}$ & $\begin{array}{c}\Phi_{\mathrm{NMR}, \mathrm{ef}} \\
{[\%]}\end{array}$ & $\begin{array}{l}S_{w} \text { irr } \\
{[\%]}\end{array}$ & $\begin{array}{c}K \\
{[\mathrm{nD}]}\end{array}$ & $\begin{array}{c}K_{\mathrm{C}} \\
{[\mathrm{nD}]}\end{array}$ & $\begin{array}{c}K_{\mathrm{SDR}} \\
{[\mathrm{nD}]}\end{array}$ & $\begin{array}{c}K_{\mathrm{WWZ}} \\
{[\mathrm{nD}]}\end{array}$ & $\begin{array}{c}\mathrm{FZI}_{\mathrm{C}} \\
{[\mu \mathrm{m}]}\end{array}$ & $\begin{array}{c}\mathrm{FZI}_{\mathrm{SDR}} \\
{[\mu \mathrm{m}]}\end{array}$ & $\begin{array}{c}\mathrm{FZI}_{\mathrm{WwZ}} \\
{[\mu \mathrm{m}]}\end{array}$ & $\mathrm{Class}$ \\
\hline 869 & 3.31 & 3.02 & 0.65 & 6.98 & 3.67 & 47.42 & 50 & 191 & 9844 & 291808 & 0.06 & 0.43 & 2.32 & 2 \\
870 & 1.86 & 3.56 & 0.26 & 5.68 & 3.82 & 32.75 & 10 & 49 & 15481 & 439030 & 0.03 & 0.50 & 2.68 & 2 \\
871 & 0.95 & 0.91 & 0.45 & 2.31 & 1.36 & 41.13 & 10 & 20 & 285 & 5836 & 0.09 & 0.33 & 1.49 & 1 \\
872 & 3.29 & 0.25 & 0.18 & 3.72 & 0.43 & 88.44 & 10 & 0.01 & 0.69 & 327 & 0.01 & 0.09 & 2.01 & 2 \\
873 & 0.66 & 0.19 & 0.22 & 1.07 & 0.41 & 61.68 & 20 & 0.19 & 1.4 & 51 & 0.05 & 0.14 & 0.85 & 1 \\
874 & 0.86 & 1.94 & 0.45 & 3.25 & 2.39 & 26.46 & 280 & 84 & 3738 & 86165 & 0.08 & 0.51 & 2.43 & 2 \\
876 & 5.05 & 0.5 & 0.31 & 5.86 & 0.81 & 86.18 & 60 & 0.13 & 9 & 3034 & 0.02 & 0.13 & 2.35 & 2 \\
877 & 0.84 & 2.22 & 1.76 & 4.82 & 3.98 & 17.43 & 10 & 8301 & 49596 & 121170 & 0.35 & 0.85 & 4.18 & 2 \\
878 & 3.29 & 3.98 & 0.95 & 8.22 & 4.93 & 40.02 & 10 & 1009 & 44301 & 102515 & 0.09 & 0.57 & 2.76 & 2 \\
879 & 0.7 & 0.33 & 0.09 & 1.12 & 0.42 & 62.50 & 10 & 0.02 & 1.34 & 57 & 0.02 & 0.13 & 0.86 & 1 \\
889 & 1.23 & 0.27 & 0.07 & 1.57 & 0.34 & 78.34 & 70 & 0.00 & 0.28 & 46 & 0.01 & 0.08 & 1.08 & 1 \\
892 & 0.8 & 1.08 & 0.64 & 2.52 & 1.72 & 31.75 & 30 & 101 & 973 & 18641 & 0.14 & 0.43 & 1.87 & 2 \\
894 & 0.62 & 0.15 & 0.03 & 0.80 & 0.18 & 77.50 & 10 & 0.00 & 0.02 & 3 & 0.01 & 0.06 & 0.76 & 1 \\
896 & 0.74 & 0.28 & 0.04 & 1.06 & 0.32 & 69.81 & 10 & 0.00 & 0.31 & 24 & 0.01 & 0.10 & 0.84 & 1 \\
\hline
\end{tabular}

Explanations: $K p 1$ - irreducible water, $K p 2$ - capillary-bound water, $K p 3$ - moveable water, $\Phi_{\mathrm{NMR}}$ - total porosity from NMR, $\Phi_{\mathrm{NMR}, \text { ef }}-$ effective porosity from NMR, $S_{W}$ irr - irreducible water saturation, $K_{\mathrm{C}}$ - permeability calculated from Coates model, $K_{\mathrm{SDR}}-$ permeability calculated from SDR model, $K_{\mathrm{WWZ}}-$ permeability calculated from clay-bound water model, $\mathrm{FZI}_{\mathrm{C}}-$ flow zone index calculated using $K_{\mathrm{C}}, \mathrm{FZI}_{\mathrm{SDR}}$ - flow zone index calculated using $K_{\mathrm{SDR}}, \mathrm{FZI}_{\mathrm{WWZ}}$ - flow zone index calculated using $K_{\mathrm{WwZ}}$, Class - classes from cluster analysis.

stant slope, e.g., 870, 878, which illustrate behavior of hydrogen nuclei in the porous space consisting of diverse diameter pores. In analyzed data sets, domination of samples with high peak for $T_{2}$ about $3 \mathrm{~ms}$ (Fig. 3) and group of concave curves are observed (Fig. 4).

\subsection{Permeability calculation and Fluid Flow Unit description}

Permeability depends on the size of connecting pore throats between pores and the pore bodies. For hydrogen nuclei in porous media, the $T_{2}$ relaxation time is mainly influenced by the pore bodies. Basing on the division into free, capillary and clay-bound water, the permeability was calculated. Values of $K p 1$ (irreducible water: clay-bound water and water closed in micropores), $K p 2$ (capillary-bound water), and $K p 3$ (moveable water) was used for two well-known permeability models: 
(1) Coates model:

$$
K_{\mathrm{C}}=\left[\left(C \varphi_{\mathrm{NMR}, \mathrm{ef}}\right)^{2}\left(\frac{K p 3}{K p 1+K p 2}\right)\right]^{2},
$$

where $\Phi_{\mathrm{NMR}, \mathrm{ef}}$ is the effective porosity from NMR [frac], $K p 3$ is the free fluid index [frac], $K p 1+K p 2$ is the bulk volume index [frac], $K$ is the permeability [mD], $C$ is the empirical coefficient, equal 10 (Coates and Denoo 1981, Coates et al. 1999).

(2) SDR model:

$$
K_{\mathrm{SDR}}=a \Phi_{\mathrm{NMR}, \mathrm{ef}}{ }^{4} T_{2}^{2} l m,
$$

where $T_{2} l m$ is the $T_{2}$ logarithmic mean [ms], $a$ is the empirical coefficient, usually equal 4 (Kenyon 1992).

Coates and SDR models work better for the high porosity and permeability samples (Kleinberg and Vinegarm 1996, Straley et al. 1997, Puskarczyk 2011, Puskarczyk and Jarzyna 2012). It was decided to add a third permeability calculation model, relating to the clay-bound water:

(3) Clay-bound water model:

$$
K_{W W Z}=\left(c \Phi_{\mathrm{NMR}, \mathrm{ef}}\right)^{4}\left(\frac{\Phi_{\mathrm{NMR}}-K p 1}{K p 1}\right)^{2},
$$

where $K p 1$ is the clay-bound water [frac], $c$ is the empirical coefficient, usually equal $10, \Phi_{\mathrm{NMR}}$ is the total porosity from NMR [frac].

This model excludes clay-bound water content but uses capillary-bound water. It is very important to take into account water closed in micropores in low porosity and low permeability samples.

Values of absolute permeability were estimated on the basis of NMR parameters (Table 3). The results of later calculations turned off to be more precise than other permeability values (Coates and Denoo 1981). Next, permeability values were used to estimate the flow zone index (FZI) values. Calculations were made on the basis of NMR parameters obtained from the interpretation (Table 3).

High correlation between effective porosity (NMR) and permeability calculated on the basis of NMR is observed (Fig. 5). There is no correlation between laboratory permeability measurement results (pink) and effective porosity (NMR). Higher determination coefficient $\left(r^{2}\right)$ for clay-bound water model (WWZ) confirmed the sense of using this approach. Results of permeability calculation using WWZ model are the closest to laboratory measurements. The WWZ model reflects the clay-bound water contribution in the total water content, which is significant in this type of rocks. 


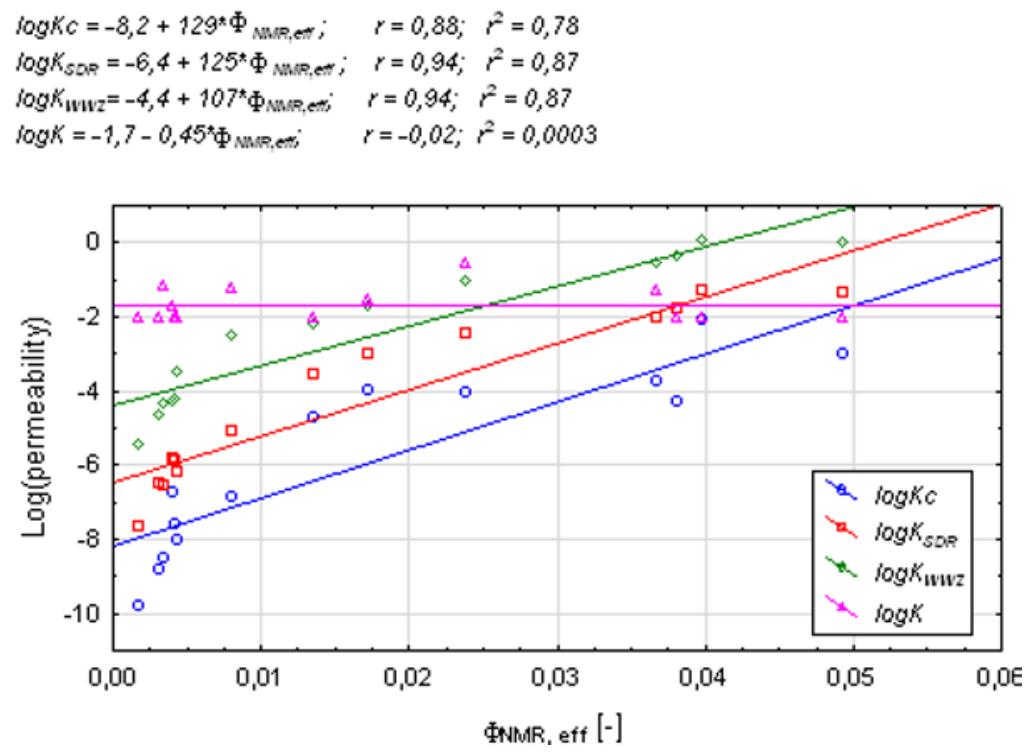

Fig. 5. Relationship between permeability versus porosity; permeability was calculated according to various formulas (symbols are explained in Table 3).

The NMR measurement provides information about effective porosity and irreducible water saturation. Permeability calculated from NMR is only estimation and logarithm of permeability versus porosity relationship could be different from linear. Flow zone index (FZI) was used to obtain Fluid Flow Unit characterization of investigated rocks (Amaefule et al. 1993). Flow zone index (FZI) includes indirect information on pore throats and also on pores and grains distributions. The FZI parameter changes according to geological features as texture and structure of the rock. A low value of FZI is related to high tortuosity and low permeability.

FZI was calculated for standard NMR interpretation results. Inspection of results revealed two groups of samples responding to two Fluid Flow Units with similar factors. For division, the cluster analysis was used. The purpose of cluster analysis is to assemble observations into relatively homogeneous groups. For the discussed data sets, cluster analysis was performed by $k$-means methods (MacQueen 1967). The $k$-mean clustering aim is to partition the observations into clusters, in which each observation belongs to the cluster with the nearest centroids. When the objects are assigned, the positions of centroids are recalculated. The procedure is repeated until the centroids movement is stopped. The members of clusters are at once alike and at the same time unlike members of other groups. There is no analytical solution to this problem, which is common to all areas of classification. 
Cluster analysis was performed for each permeability model (1)-(3) (Table 3). Results of classification were the same. For further analysis, the WZ model (3) was chosen, because of the best fitting results. It was decided that this model provided the best permeability estimation for the analyzed data.

The first class comprised samples number $871,873,879,889,894$, and 896 with FZI values less than $1.8 \mu \mathrm{m}$ and the second one - samples number $869,870,872,874,876,877,878$, and 892 with FZI above $1.8 \mu \mathrm{m}$ (Fig. 6). The FZI cutoff was selected after statistical analysis (histograms, scatterplots, etc.) of the total FZI values from the whole data set. The highest value of determination coefficients $r^{2}$ of $\log$ permeability versus porosity function was obtained within both groups of data for WWZ model in comparison to other two models. The same relationship for the full data set achieved the highest correlation coefficient but authors decided to keep the division into two separate groups. The red group (FZI $\leq 1.8 \mu \mathrm{m})$ of effective porosity less than $1.5 \%$ (average $0.5 \%$ ) and permeability less than $0.005 \mathrm{mD}$ (average $0.001 \mathrm{mD}$ ) represented the Carboniferous and some Cambrian samples. The blue group (FZI $>1.8 \mu \mathrm{m}$ ) of higher porosity (average effective porosity equal to $2.7 \%$ ) and permeability (average $0.38 \mathrm{mD}$ ) consisted mainly of the Cambrian samples. The Permian sample was classified in the red group and two Silurian samples in both groups.

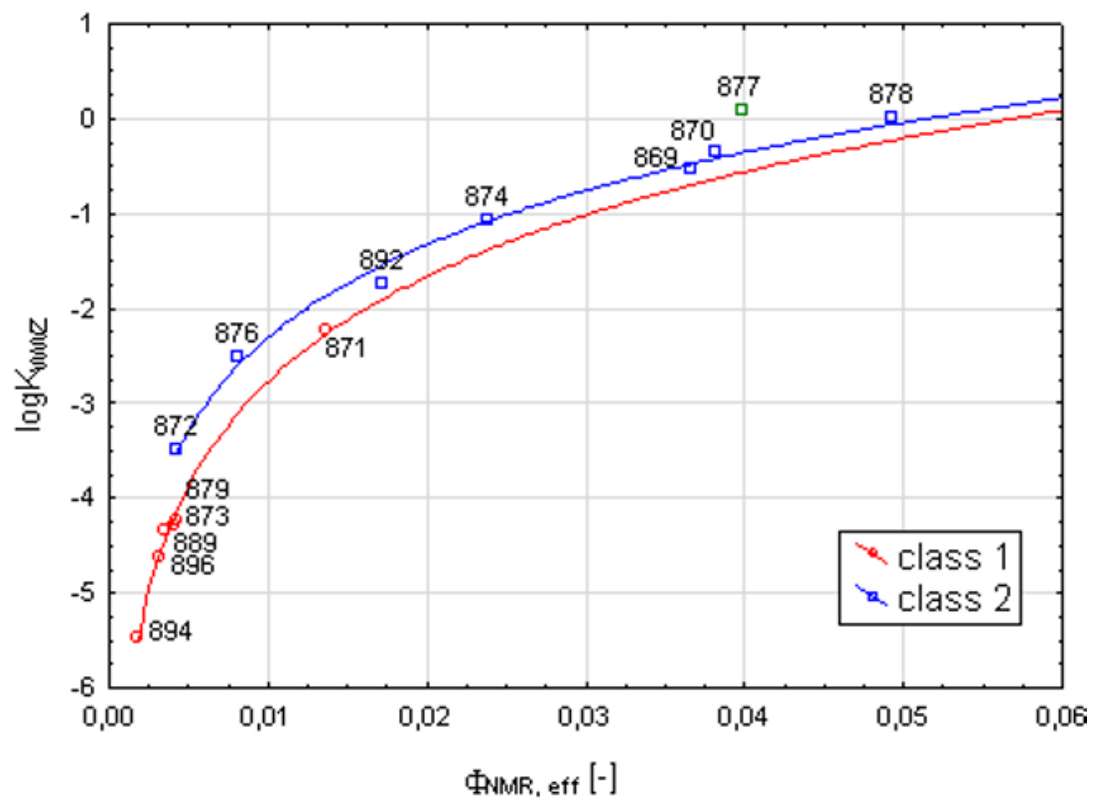

Fig. 6. Permeability versus porosity relationship according to FZI division; improved NMR interpretation using WWZ permeability calculation model. 


\subsection{Visualization and processing of mercury porosimetry results}

Mercury porosimetry is a well-known and useful technique of porous space investigation and provides the following parameters: total intrusion volume, median pore diameter-volume, median pore diameter-area, average pore diameter, porosity, threshold pressure, characteristic length, and tortuosity (Pittman 1992, Vavra et al. 1992, Webb 2001). Mercury porosimetry measurements were performed using porosimeter AutoPore IV 9500.

Improved approach of presentation and processing of mercury porosimetry data was applied to obtain relationships between the reservoir parameters: effective porosity $(\Phi m p)$, permeability $(K)$, and other factors from NMR (Table 3) and Swanson parameter (Swanson 1980, Thomeer 1983). Computerized processing of cumulative volume of mercury versus pressure from porosimetry curves provided automatic coordinates for Swanson parameter calculation (Wojtanowski 2011) (Fig. 7).

Computerized processing of selected mercury porosimetry results revealed 3 porous systems in the majority of rocks. Each porous system was characterized by Thomeer hiperbola presented in pressure [psi] versus volume of mercury $[\mathrm{mL} / \mathrm{g}]$ coordinate frame (Fig. 7), Swanson parameter (coordinates: $S p c$ versus $S b v$ ), threshold pressure or extrapolated displacement pressure $(P d)$, and total porosity of system $(B v)$. Swanson parameter coordinates are defined as bulk volume of mercury $(B v)$ and pore pressure $(P c)$ at the inflection point on the $P c$ versus $B v$ plot. Swanson parameter may be also defined as the apex at the plot of $B v / P c$ versus Bv (Mao et al. 2013). Threshold pressure $(P d)$ and total porosity $(B v)$ of selected pore systems mean pressure at which mercury starts to intrude into pore system and bulk volume occupied by mercury, respectively. For each system, average pore diameter was also determined on the basis of mercury volume versus pore
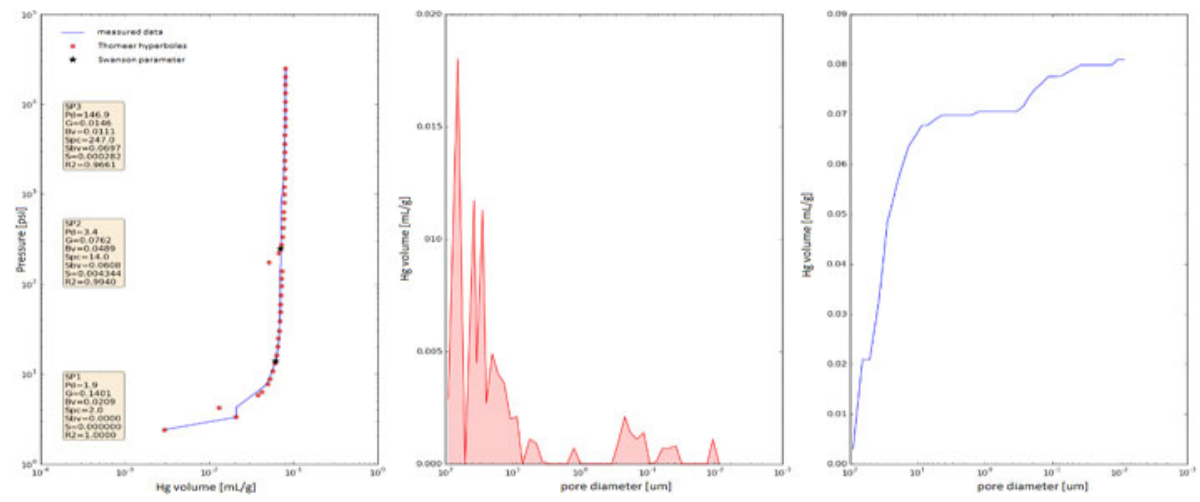

Fig. 7. Result of computerized processing of the mercury cumulative volume versus pressure for 892 sample; three pore systems were distinguished. 
diameter plot. Relationships between selected variables turned out to be quite strong and useful in determining porosity and pore diameters. Swanson parameter was also well correlated with individual parameters, i.e., threshold pressure and total porosity and also with the specific reservoir parameter calculated as the square root of permeability and porosity (Jarzyna and Puskarczyk 2010, Xiao et al. 2008). Presented plots and statistical formulas are the tools for calculating extreme values of porosity and determining low pore diameter range on the basis of computerized processing results. Also, results of porosimetry harmonize with NMR outcomes and micro-CT solutions.

Several examples of relationships between various parameters characterizing pore space of examined rocks are presented (Figs. 8-11) and discussed. Of great importance is the strong correlation between average pore diameters in pore systems and pressure values at which mercury intrudes into pore system. Results for various pore systems illustrated by different hyperbolas determined in automatic processing of mercury porosimetry outcomes matched to the same relationship (Fig. 8).

The definition of Swanson parameter pointed out its close relationship with bulk volume of mercury in pore system. Dispersion of data in Fig. 8 was caused by not fully precise hyperbola matching to the measured data. The first pore system assigned to the highest volume of intruded mercury revealed the best correlation (Fig. 9). Two other pore systems assigned to low bulk volumes of mercury (and low diameters of pores) cannot be distin-

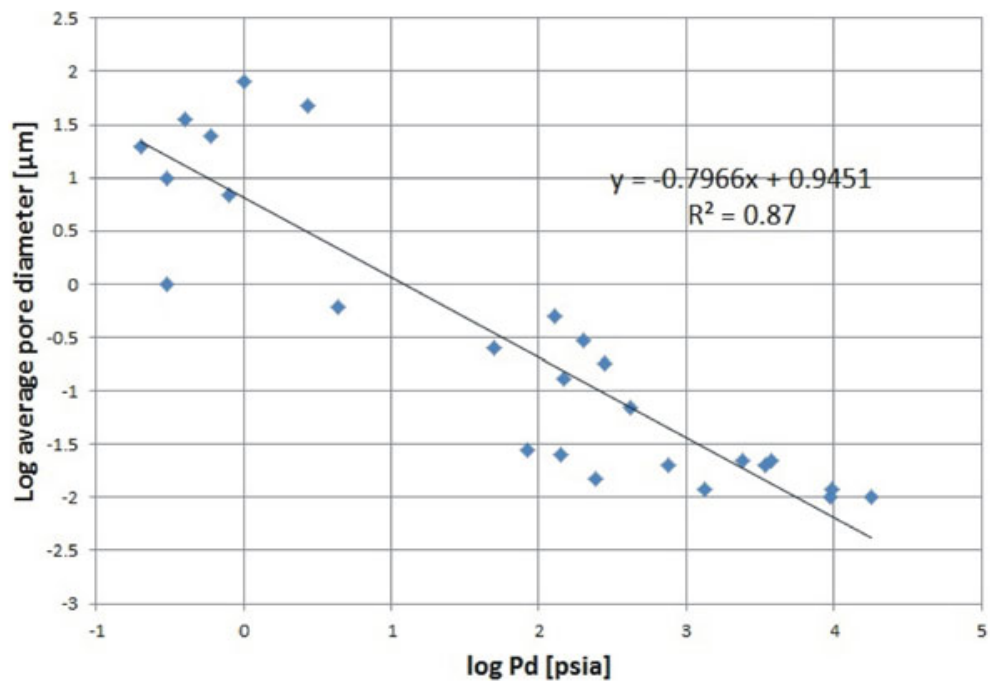

Fig. 8. Relationship between the average pore diameter in pore systems and the threshold pressure, $P d$. 


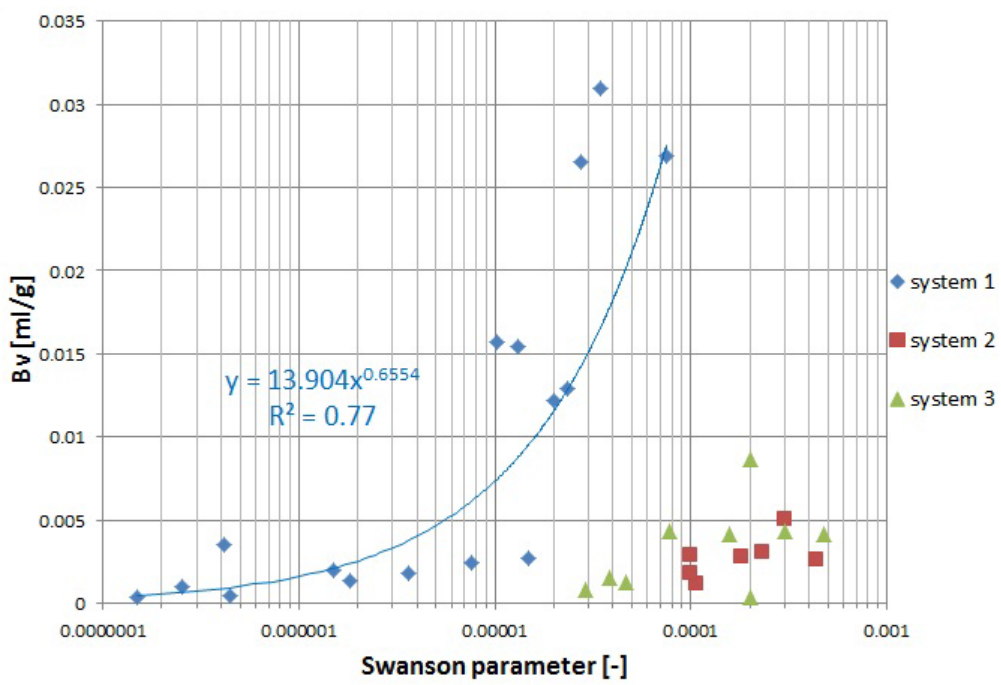

Fig. 9. Relationship between bulk volume occupied by mercury for each pore system $B v$ and the Swanson parameter.

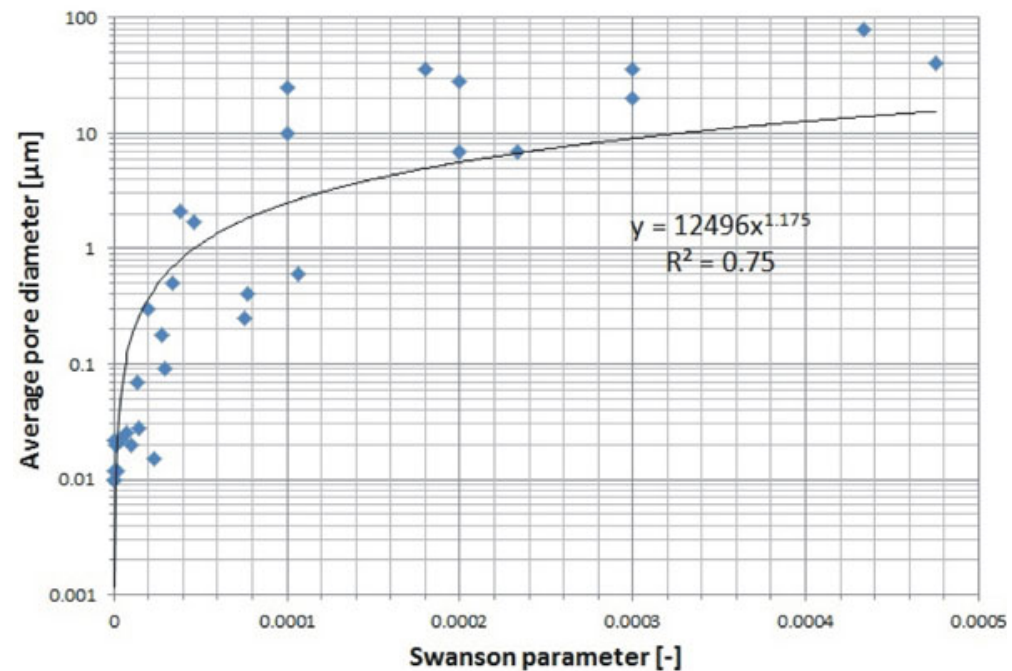

Fig. 10. Relationship between the average pore diameter in pore systems and the Swanson parameter.

guished. It means that the applied criteria for distinguishing the Thomeer hyperbolas did not work properly in each case. Swanson parameter well correlates also with average pore diameter in pore systems (Fig. 10). This relationship holds true for the full data set. 


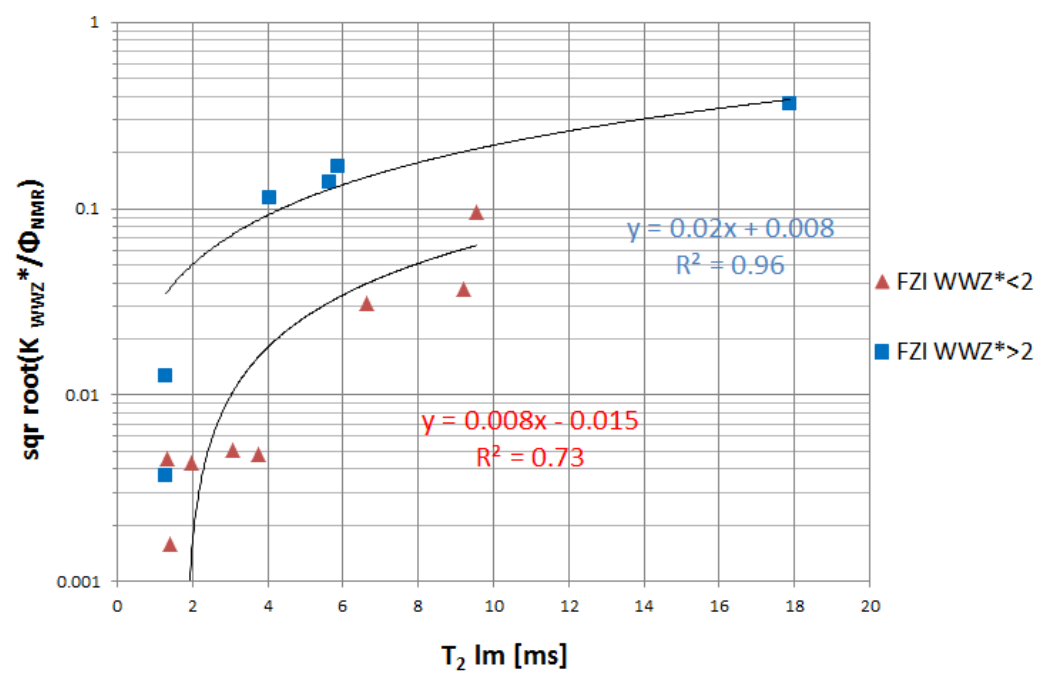

Fig. 11. Relationship between square root of the ratio of permeability calculated using WWZ model to the total porosity from NMR versus $T_{2}$ logarithmic mean, $T_{2} l m$.

An attempt to combine the NMR results with the MP results was made. Relationships between specific petrophysical parameter defined as square root of permeability and porosity ratio versus $T_{2}$ logarithmic mean showed high determination coefficients (Fig. 11). Samples were grouped in FZI $\mathrm{WwZ}_{\mathrm{W}}$ manner.

Similarity of cumulative NMR $T_{2}$ distributions and MP results is presented in Figs. 12-15. Analysis of the plots explains also the dispersion of data in the relationships presented above and sheds light into different ranges of amplitude of NMR distributions, different arrivals of signals and shows various pore systems revealed in porosimetry. From the whole group of cumulative $T_{2}$ distributions, only Cambrian samples indicate almost flat (constant gradient) run of the curves, which gives the information that pores of different diameters but still in the low range simultaneously took part in fluid flow. Figures 12-15 show that in low porosity and low permeability samples, the mercury volume increases stepwise (only three from the 14 samples: one Carboniferous and two Cambrian samples do not follow these ways). It means that the mercury had to force the narrow and complex pore throats or had to imbibe by the opening microfractures. For this group of samples, two pore systems were distinguished: one relating to the pore system and second to the fracture system. The rest of the analyzed samples are characterized with the cumulative $T_{2}$ distribution curves reflecting the pores' size in the range of irreducible water saturation and capillary-bound water saturation (subcapillary and capillary pore diameters). 


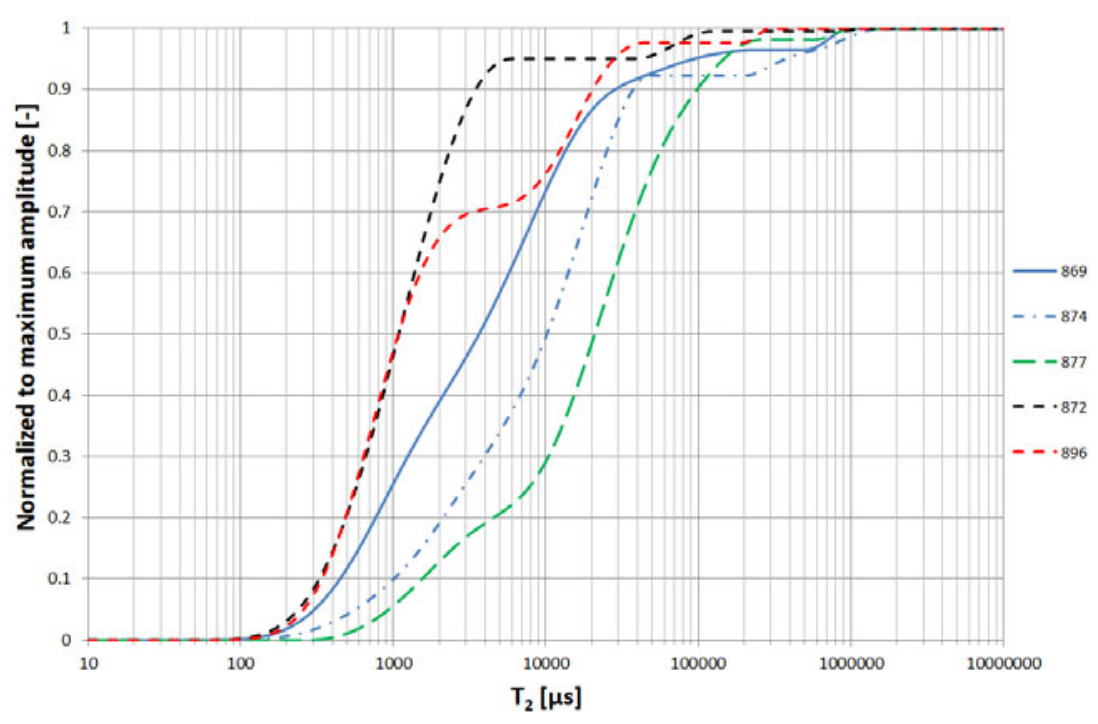

Fig. 12. Cumulative $T_{2}$ distributions of NMR signals for selected samples. Colours as in Fig. 3.

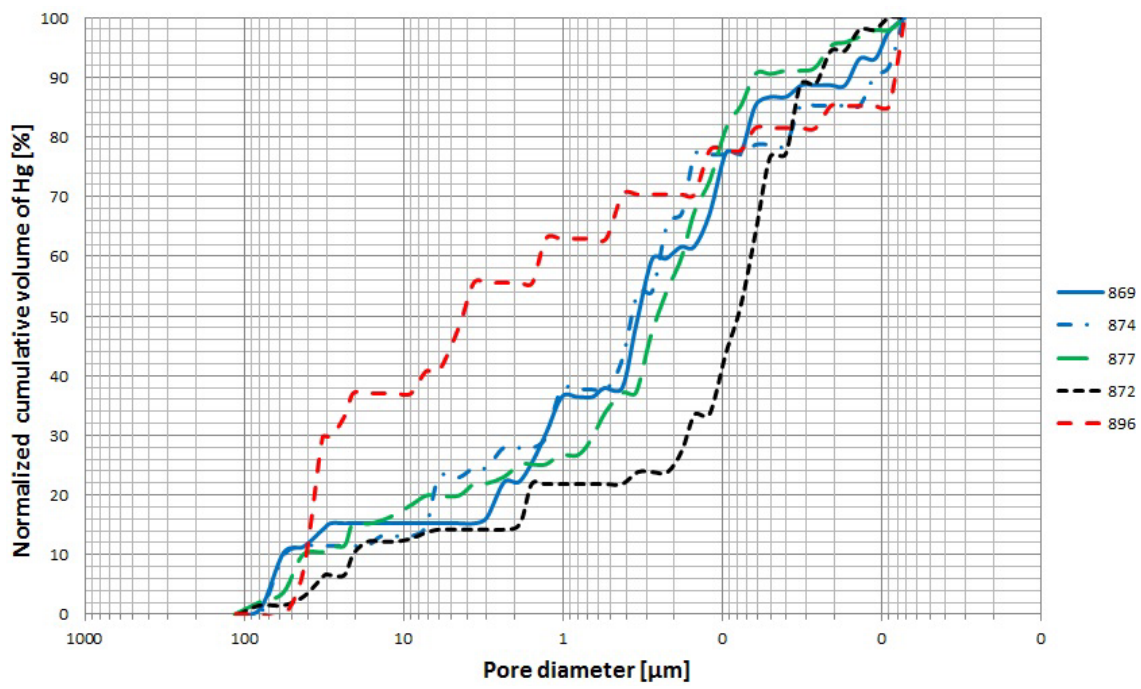

Fig. 13. Mercury porosimetry results for selected samples. Colours as in Fig. 3.

An influence of clay minerals volume was observed in the NMR and porosimetry cumulative curves behavior. Samples characterized with higher clay content have a convex run of the curve (sample No. 872, clay volume equal to $17 \%$ ) while the concave curves pertain to low clay content samples 


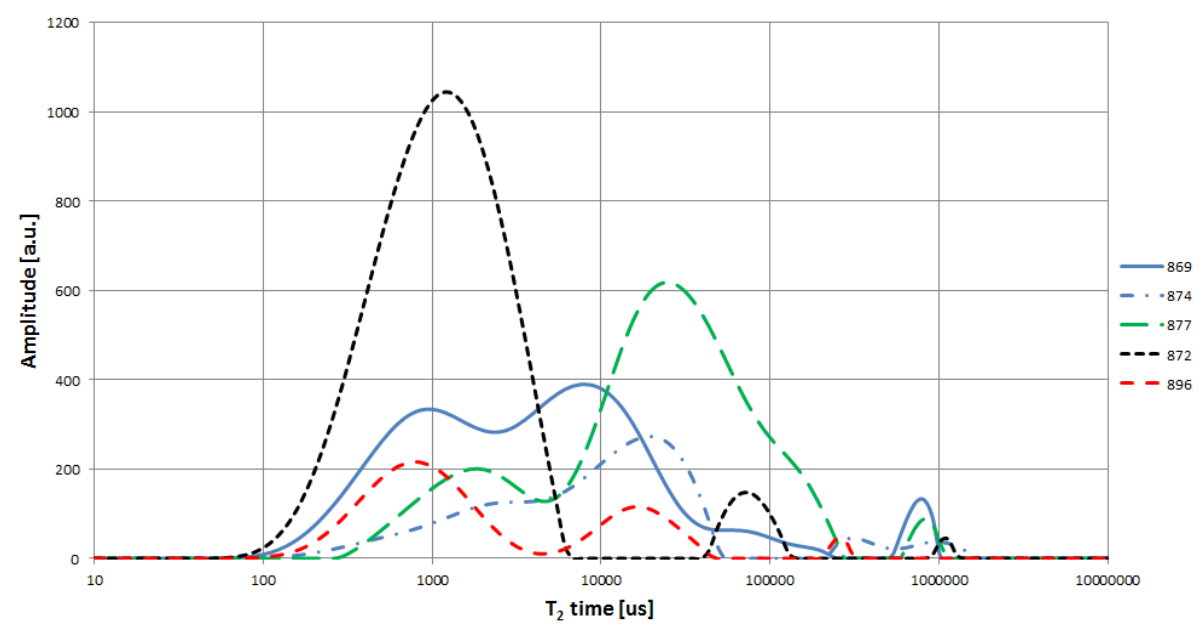

Fig. 14. $T_{2}$ distributions for selected samples. Colours as in Fig. 3.

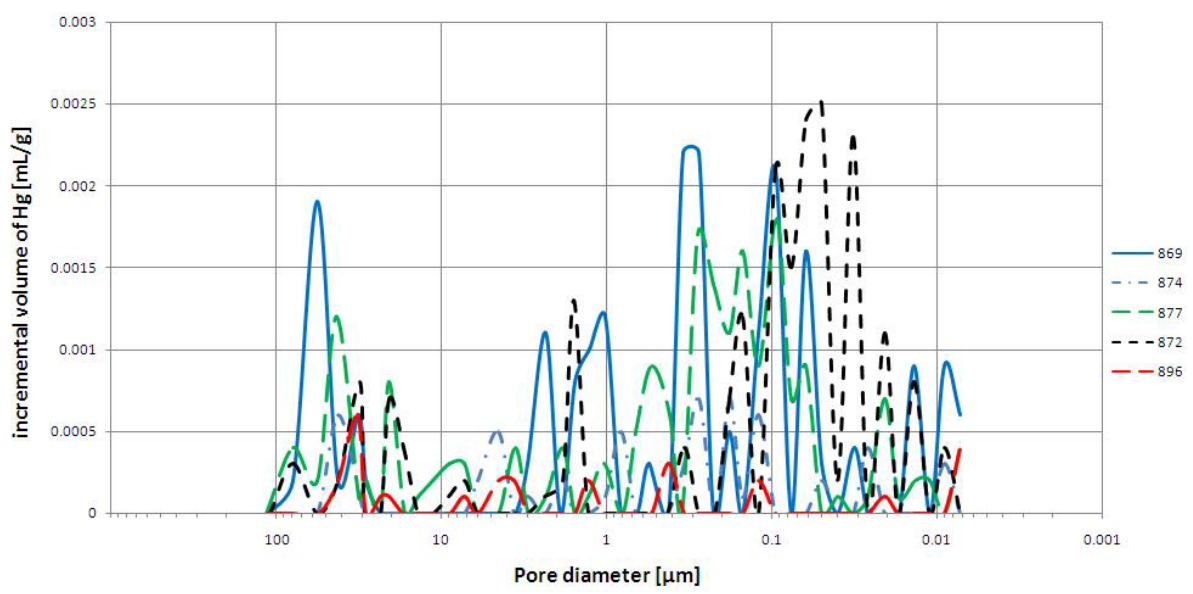

Fig. 15. Incremental volume of mercury versus pore diameter for selected samples. Colours as in Fig. 3.

(sample No. 896, clay volume equal to $21 \%$ ) which is also reflected in incremental volume of mercury (Fig. 14).

Joint analysis of NMR curves and MP plots gave the data set for calculating a relationship between pore diameter and $T_{2}$ time. Immediate comparison of $T_{2}$ distributions (Fig. 14) and incremental volume of mercury (Fig. 15) is rather difficult, but detailed inspection of the sequences of maxima on both plots enables mutual assigning of pore diameter and $T_{2}$ time distribution. 


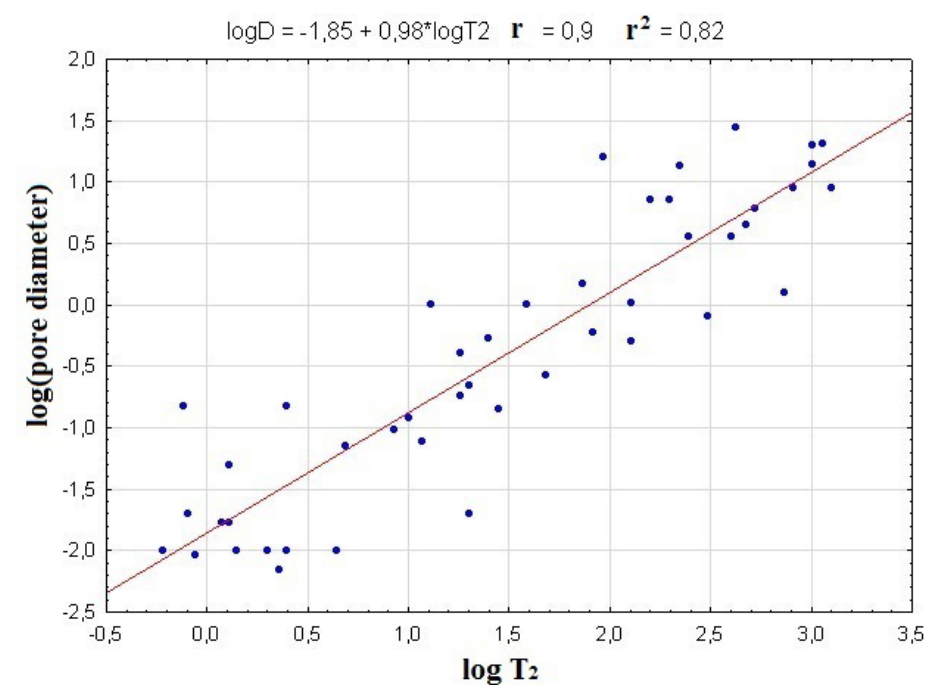

Fig. 16. Relationship between logarithm of pore diameter and logarithm of transverse relaxation time, $T_{2}$.

On the basis of the data collected, the correlation relation between the relaxation time $T_{2}$ and the pore diameter was calculated. Despite of complicated pore and fracture systems in analysed samples, the correlation coefficient was high $(r=0.9)$. Linear regression (Fig. 16) was observed for logarithm value of pore diameter and $T_{2}$ time (determination coefficient equal $r^{2}=$ 0.82 ). The equation obtained can be used for pore size estimation based on NMR measurements.

\subsection{Computed microtomography (micro-CT, $\mu$-CT)}

Computed microtomography is one of the modern, non-destructive research methods allowing to investigate the object using X-rays and present the pore space image of the examined sample (Zalewska et al. 2010, Bielecki et al. 2012, Dohnalik 2013). Processing of the 3D $\mu$-CT image provides the information about porosity, number and length of the pore channels, their connections, directions of fluid flow, and structure. Results of $\mu$-CT enable also permeability modelling (Arns et al. 2005, Bielecki 2011). The measurements were performed using Benchtop CT160 microtomograph. The results of the $3 \mathrm{D}$ visualization of the pore space were obtained using AVIZO software and were illustrated in the video form, colouring pore space in green and rock matrix in grey. MAVI software allowed determination of the qualitative petrophysical information which was presented graphically (Figs. 17 and 18) and numerically (Figs. 19-22). 


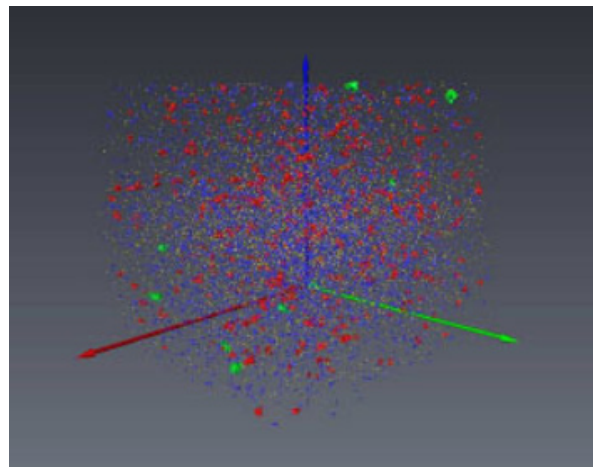

Fig. 17. Microtomographic characteristics, sample No. 871 .

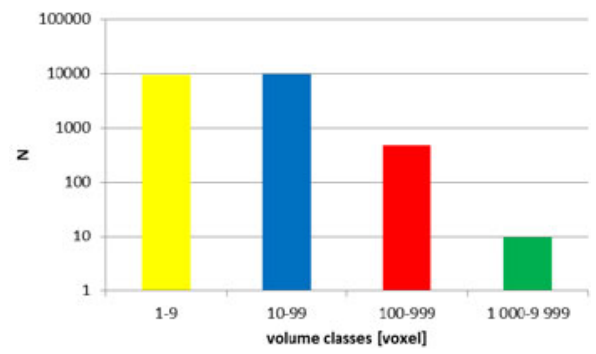

Fig. 19. Number of porosity subgroups (N) refers to volume class, sample No. 871 .

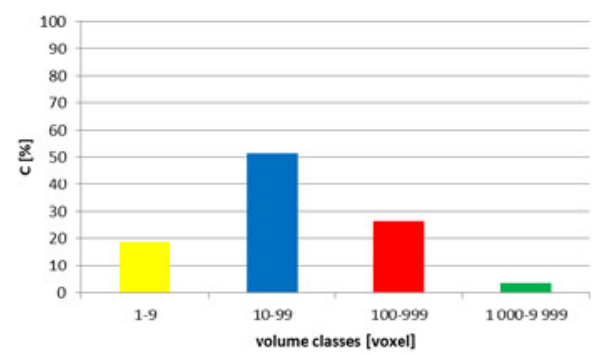

Fig. 21. Volume class percentage $(C)$ Fig. 22. Volume class percentage $(C)$ referring to class volume, sample No. 871. referring to class volume, sample No. 876.

The results of porosity determination were based on the pore space division into subgroups. Each subgroup consists of the pores connected with each other but not communicated with pores from other subgroups. Subgroups are divided into classes regarding their volume. Volume class unit is voxel. In the presented results 1 voxel [v] is equal to $5.8 \times 5.8 \times 5.8=$ 
$195 \mu \mathrm{m}^{3}$ and is the smallest volume which could be detected using Benchtop CT160 microtomograph and available samples. Spatial visualization of the pore space is made at the beginning. The visualized sample is cuboid with the size $950 \times 950 \times 400 \mathrm{v}$, measured in the $X, Y$, and $Z$ directions. The subsample size is equal to $1 / 4$ of the whole sample size $(475 \times 475 \times 400 \mathrm{v})$. The effect of the further analysis is the distinction of the six volume classes of the subgroups in the whole visualized pore space (Table 4).

Table 4

Description of classes

\begin{tabular}{|c|c|c|c|c|c|c|}
\hline $\begin{array}{c}\text { Class } \\
\text { volume }\end{array}$ & I & II & III & IV & V & VI \\
\hline $\begin{array}{c}\text { Number } \\
\text { of voxels }\end{array}$ & $1-9$ & $10-99$ & $100-999$ & $1000-9999$ & $10000-99999$ & $>100000$ \\
\hline $\begin{array}{c}\text { Maximum } \\
\text { number of } \mu \mathrm{m}^{3}\end{array}$ & 1755 & 19305 & 194805 & 1949805 & 19499805 & $>19500000$ \\
\hline
\end{tabular}

Figures 17 and 18 visualize the distribution of the pores classes, where each volume classes correspond to the one colour, i.e., I - yellow, II - blue, III - red, IV - green, V - white, and VI - violet. Graphs in two versions are presented in Figs. 19-22. The first group (Figs. 19 and 20) presents the number of subgroups in particular volume class what refers to class splitting. The second group (Figs. 21 and 22) presents the volume of class contribution in the total pore space volume in percentage. The micro-CT results are presented for two sandstone samples: 871 and 876 (Figs. 17-22) showing the difference in the pore network (Figs. 17 and 18). Sample No. 876 revealed higher porosity than sample No. 871. Pore space distributions are different in these two samples. Red subgroups (100-999 v) are concentrated in one part of the sample No. 876 and sample No. 871 occurs to be more homogenous. Sample No. 876 is more porous but less homogenous. Porosity calculated from computed microtomography for sample No. 871 is equal to $\Phi \mu-\mathrm{CT}=0.5 \%$ and for sample No. $876 \Phi \mu$-CT $=2.6 \%$. Porosity from computed microtomography, $\Phi \mu$-CT, was lower than porosity calculated from standard laboratory measurements (Table 2).

Comparison of the subgroup numbers in the particular volume class (Table 5) provides information that the most diverse pore space is in the Cambrian and Ordovician samples. The Permian sample is characterized by irregular pores distribution. Within the subgroups with the smallest volume (class I and II), one subgroup belongs to class V. The Carboniferous samples are mainly composed of subgroups from classes I and II. 


\section{Table 5}

Number of subgroups in the volume classes

\begin{tabular}{|c|c|c|c|c|c|c|}
\hline No. & I & II & III & IV & V & VI \\
\hline 869 & 27406 & 23253 & 1581 & 124 & 7 & - \\
870 & 22395 & 74821 & 2212 & 75 & - & - \\
871 & 9310 & 9718 & 478 & 10 & - & - \\
872 & 62183 & 92182 & 3576 & 12 & - & - \\
873 & 54450 & 53489 & 134 & - & - & - \\
874 & 50781 & 51647 & 922 & 6 & - & - \\
876 & 51326 & 60826 & 598 & - & - & - \\
877 & 62615 & 82790 & 2982 & 200 & 8 & - \\
878 & 42818 & 33726 & 692 & 31 & 8 & 2 \\
879 & 25623 & 13042 & - & - & - & - \\
889 & 54036 & 44096 & 127 & - & 1 & - \\
892 & 17009 & 37397 & 84 & 1 & - & - \\
894 & 95853 & 91307 & 553 & 9 & - & - \\
896 & 16435 & 12912 & 47 & - & - & - \\
\hline
\end{tabular}

Another important issue is related to fluid flow capability. Analyzed samples are in general impermeable or having permeability less than $0.01 \mathrm{mD}$ (it was confirmed by micro-CT images in voxel resolution). Micro$\mathrm{CT}$ analysis proved that there is no connection between pores subgroup from the opposite walls of the analyzed sample (cuboid). It means there is no fluid flow capability. Only 3 from the 14 samples indicated pore connections between the opposite walls. These samples, one Cambrian (No. 878) and one Ordovician (No. 877), are composed of subgroups from higher classes (class $\mathrm{V}$ and VI). One Cambrian sample (No. 876) consisting of subgroups I-III reached also the opposite walls connection.

Fractures and microfractures can be observed in the microtomographic images, as in Fig. 23. The qualitative estimation of complexity of pore space structure plays an important role in rock susceptibility to hydraulic fracturing. Thanks to microtomographic image, the initial evaluation of pore space homogeneity can be realized. From the whole data set, the Cambrian samples are characterized by the most uniformly distributed pores, which may indicate the controlled fracturing process but on the other hand difficulties in the fracturing itself.

High resolution of computed tomography, its ability to detect pores in micro and nano scale and determine mutual connections between them is crucial in the case of analyzing tight formations. Micro-CT results are useful 


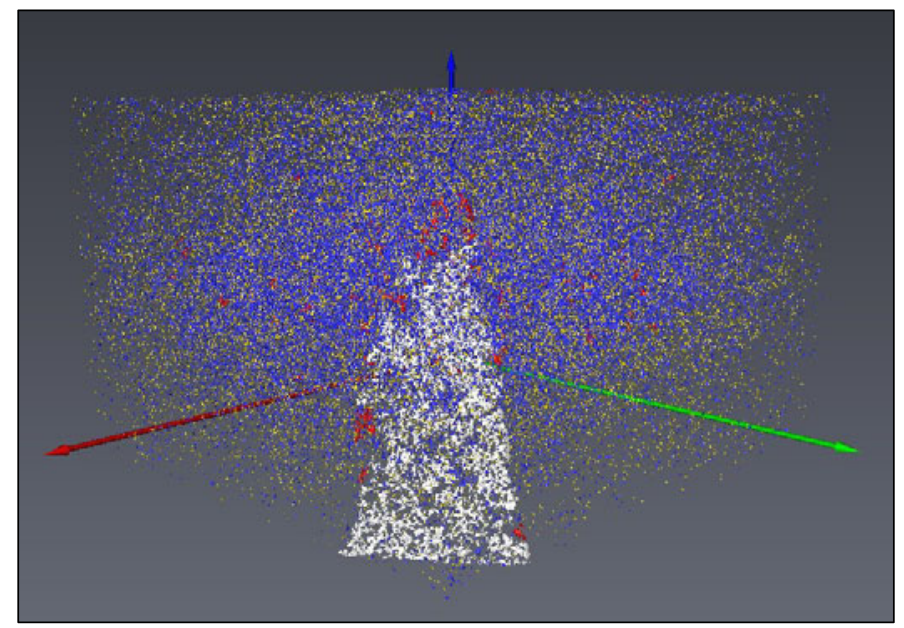

Fig. 23. Microtomographic image of the Carboniferous sandstone, microfractures marked in white; sample No. 889.

for estimation of fluid flow capability in pore space, mainly because the fluid flow is realized in macro- and mezopores (natural and after fracturing) (Montaron 2008). Nowadays, computed tomography offers measurement also in nano scale, which could be more useful in tight formation analysis than the one proposed there.

\section{DISCUSSION AND CONCLUSIONS}

Combination of the results from various methods with different physical background turned out to be an effective tool in examination of hard, lowporosity, and low-permeability old formations. Signals from various methods provided different porosity values and by joining them together new characteristics of the reservoir properties of investigated rocks were revealed. Differences in porosity values obtained from NMR, MP, and microCT were visible. Porosity from NMR was generally higher than from the other methods because of receiving the signal from the all pores and fractures systems in the pore samples. Porosity from micro-CT is lower and connected with the tool resolution. MP results indicated the microfracturing process occurring in the samples during the measurements.

The most justified method from the point of physical background in porosity determination is the NMR measurement. In the analyzed case, the micro-CT takes into account pores larger than $5.8 \times 5.8 \times 5.8 \mu \mathrm{m}^{3}$, which, in the case of tight formations, underestimates the porosity value but is crucial to estimate the fluid flow capability. Porosimetry together with micro-CT give the information about the pores distribution. However, porosimetry is the de- 
structive method and the influence of mercury injection on core sample should be taken into account (overestimated effective porosity). Standard porosity measurements (pycnometer) meet requirement as a reference measurement of total porosity.

The NMR signals and $T_{2}$ relaxation time distributions, cumulated curves of effective porosity and pore geometry distributions related to components of the rock porous space. Also graphs of cumulated pore specific surface were used for qualitative description of the porous space in rocks. Permeability calculated from NMR interpretation parameters is more accurate than standard laboratory measurements for low porosity, low permeability reservoirs in analyzed case, and available equipment. The cluster analysis and FZI approach lead to more precise information about fluid flow abilities. In addition to giving standard parameters like effective porosity, average pore diameter or tortuosity, the MP may be also analyzed in terms of hydraulic properties. Swanson parameter is defined at the point in which mercury fills the connected pores responsible for the permeability and starts to squeeze into blind pores. Integration of NMR and MP results enabled getting the information on pore diameter and extrapolation of the relationship to lower pores.

Microtomography allowed analyzing the pore space structure: pores orientation in pore space formation, microfractures presence and their directions, porosity values and distribution. Micro-CT images informed about the pore space parameters graphically and numerically. 3D investigations in micro-CT explained the complexity of pore space in tight rocks.

A new approach to combine the results of various methods for the effective analysis of tight, low porosity, and low permeability rocks is needed with the aim of not omitting the potential of tight reservoirs.

Acknowledgments. The authors express their gratitude to Polish Ministry of the Environment and Polish Geological Institute - National Research Institute, Warsaw, Poland, for the data. Laboratory measurements apart from mercury porosimetry were done in the Oil and Gas Institute, Kraków, Poland. Mercury porosimetry measurements were done in AGH UST, Faculty of Geology Geophysics and Environment Protection, Department of Fossil Fuels by Roman Semyrka, Ph.D. eng.

The project was founded by the National Science Centre on the basis of decision DEC-2011/03/N/ST10/05354, No. AGH 18.18.140.244.

Research was also financially supported by AGH UST FGGEP grant No. 15.11.140.053 for Ph.D. students in 2011 and statutory funds at AGH UST FGGEP, Kraków, Poland. 


\section{References}

Amaefule, J.O., M. Altunbay, D. Tiab, D.G. Kersey, and D.K. Keelan (1993), Enhanced reservoir description: using core and $\log$ data to identify hydraulic (flow) units and predict permeability in uncored intervals/wells. In: $S P E$ Ann. Technical Conference and Exhibition, 3-6 October 1993, Houston, USA, SPE 26436-MS, 205-220, DOI: 10.2118/26436-MS.

Andrew, E.R. (1969), Nuclear Magnetic Resonance, Cambridge University Press, Cambridge.

Arns, C.H., F. Bauget, A. Ghous, A. Sakellariou, T.J. Senden, A.P. Sheppard, R.M. Sok, W.V. Pinczewski, J.C. Kelly, and M.A. Knackstedt (2005), Digital core laboratory: Petrophysical analysis from $3 \mathrm{~d}$ imaging of reservoir core fragments, Petrophysics 46, 4, 260-277.

Bakun-Czubarow, N. (1984), Petrology and elements of geochemistry.In: J. LeliwaKopystyński and R. Teisseyre (eds.), Constitution of the Earth's Interior. Vol. 1, Physics and Evolution of the Earth's Interior, PWN - Polish Scientific Publ., Warszawa, Elsevier, Amsterdam, 326-357.

Bielecki, J. (2011), Investigation of complex structures by means of computed tomography method, Ph.D. Thesis, Institute of Nuclear Physics, Polish Academy of Sciences, Poland.

Bielecki, J., S. Bożek, E. Dutkiewicz, R. Hajduk, J. Jarzyna, J. Lekki, T. Pieprzyca, Z. Stachura, Z. Szklarz, and W.M. Kwiatek (2012), Preliminary investigations of elemental content, microporosity, and specific surface area of porous rocks using PIXE and X-ray microtomography techniques, Acta Phys. Pol. 121, 2, 474-479.

Coates, G., and S. Denoo (1981), The producibility answer product, The Tech. Rev. 29, 2, 54-63.

Coates, G.R., L. Xiao, and M.G. Prammer (1999), NMR logging. Principles and Applications, Haliburton Energy Services, Huston, 234 pp.

Czekański, E., and Group in POGC Co. (2012), Carboniferous - prospects of new hydrocarbon reservoirs discoveries, Sci. Works Oil and Gas Inst.182 (in Polish).

Dadlez, R., S. Marek, and J. Pokorski (2000), Geological map of Poland without Cainozoic deposits, scale 1:1 000 000, Polish Geological Institute, Warsaw, Poland.

Dohnalik, M. (2013), Improving the ability of determining reservoir rocks parameters using X-ray computed microtomography, Ph.D. Thesis, AGH University of Science and Technology, Kraków, Poland.

Jarzyna, J., and E. Puskarczyk (2010), Nuclear magnetic resonance (NMR) and mercury porosimetry measurements for permeability determination. In: G. Christofides et al. (eds.), Proc. 19th Congress of the Carpathian-Balkan Geological Association, 23-26 September 2010, Thessaloniki, Greece, Scientific Annals, School of Geology, Sp. Vol. 99, 371-376. 
Jarzyna, J.A., P.I. Krakowska, and E. Puskarczyk (2012), Tight Precambrian and Paleozoic reservoirs in the light of petrophysical analysis. In: Proc. 74th EAGE Conference and Exhibition incorporating EUROPEC 2012, 4-7 June 2012, Copenhagen, Denmark, DOI: 10.3997/2214-4609.20148228.

Jaworowski, K., and Z. Mikołajewski (2007), Oil- and gas-bearing sediments of the Main Dolomite (Ca2) in the Międzychód region: a depositional model and the problem of the boundary between the second and third depositional sequences in the Polish Zechstein Basin, Prz. Geol. 55, 12/1, 1017-1024 (in Polish).

Liu, Z.H., C.C. Zhou, L.H. Zhang, D.J. Dai, C.L. Li, L. Zhang, G.Q. Liu, and Y.J. Shi (2007), An innovative method to evaluate formation pore structure using NMR logging data. In: Proc. SPWLA 48th Annual Logging Symposium, 3-6 June 2007, Austin, USA, SPWLA-2007-S.

MacQueen, J.B. (1967), Some methods for classification and analysis of multivariate observations. In: Proc. 5th Berkeley Symp. Mathematical Statistics and Probability, University of California Press, Berkeley, 281-297.

Mao, Z.-Q., L. Xiao, Z.-N. Wang, Y. Jin, X.-G. Liu, and B. Xie (2013), Estimation of permeability by integrating nuclear magnetic resonance (NMR) logs with mercury injection capillary pressure (MICP) data in tight gas sands, Appl. Magn. Reson. 44, 4, 449-468, DOI: 10.1007/s00723-012-0384-z.

Monk, D. (2013), Unconventional reservoir sweet spots from geophysics (editorial), Oilfield Rev. Winter 2013/2014, 1.

Montaron, B. (2008), Connectivity theory - a new approach to modeling "nonArchie" rocks. In: Proc. SPWLA 49th Annual Logging Symposium, 25-28 May 2008, Edinburgh, Scotland, SPWLA-2008-GGGG.

Pittman, E.D. (1992), Relationship of porosity and permeability to various parameters derived from mercury injection-capillary pressure curves for sandstone, AAPG Bull. 76, 2, 191-198.

Puskarczyk, E. (2011), Assessment of reservoir properties of rock through nuclear magnetic resonance phenomenon application, Ph.D. Thesis, AGH University of Science and Technology, Kraków, Poland (in Polish).

Puskarczyk, E. and J. Jarzyna (2012), New method of NMR signals fitting using 'Distribution' program. In: Proc. 74th EAGE Conference and Exhibition incorporating EUROPEC 2012, 4-7 June 2012, Copenhagen, Denmark, DOI: $10.3997 / 2214-4609.20148554$.

Semyrka, G., J. Jarzyna, R. Semyrka, M. Kaźmierczuk, and L. Pikulski (2010), Reservoir parameters of lithostratigraphic successions of the lower Paleozoic strata in the Polish part of the Baltic region based on laboratory studies and well logs, Geol. Quart. 54, 2, 227-240.

Straley, Ch., D. Rossini, H. Vinegar, P. Tutunjian, and Ch. Morriss (1997), Core analysis by low-field NMR, The Log Analyst 38, 2, 84-94. 
Such, P., G. Leśniak, and M. Słota (2010), Quantitative porosity and permeability characterization of potential Rotliegend tight gas reservoir, Prz. Geol. 58, 4, 345-351 (in Polish).

Swanson, B.F. (1981), A simple correlation between permeabilities and mercury capillary pressures, J. Petrol. Technol. 33, 12, 2498-2504, DOI: 10.2118/ 8234-PA.

Thomeer, J.H. (1983), Air permeability as a function of three pore-network parameters, J. Petrol. Technol. 35, 4, 809-814, DOI: 10.2118/10922-PA.

Vavra, C.L., J.G. Kaldi, and R.M. Sneider (1992), Geological applications of capillary pressure: A review, AAPG Bull. 76, 6, 840-850.

Webb, P.A. (2001), An introduction to the physical characterization of materials by mercury intrusion porosimetry with emphasis on reduction and presentation of experimental data, Micrometrics Instrument Corp., Norcross, USA.

Wojtanowski, K. (2011), Algorithm and application program to processing and interpretation of capillary pressure data, M.Sc. Thesis, AGH University of Science and Technology, FGGEP, Kraków, Poland.

Xiao, L., Z.Q. Mao, Z.X. Xiao, and C. Zhang (2008), A new method to evaluate pore structure consecutively using NMR and capillary pressure data. In: Proc. SPWLA 49th Annual Logging Symposium, 25-28 May 2008, Edinburgh, Scotland, SPWLA-2008-AA.

Xiao, L., X.-P. Liu, C.-C. Zou, X.-X. Hu, Z.-Q. Mao, Y.-J. Shi, H.-P. Guo, and G.-R. Li (2014), Comparative study of models for predicting permeability from nuclear magnetic resonance (NMR) logs in two Chinese tight sandstone reservoirs, Acta Geophys. 62, 1, 116-141, DOI: 10.2478/s11600-0130165-6.

Zalewska, J., M. Dohnalik, J. Kaczmarczyk, A. Poszytek, G. Sikora, D. Cebulski, M. Masłowski, and E. Biały (2010), X-ray computed microtomography in examination of carbonate rocks, Sci. Works Oil and Gas Inst. 171, 1-263 (in Polish).

Zalewska, J., M. Dohnalik, G. Łykowska, and J. Kiernicki (2011), Laboratory of the rocks and reservoir fluids geophysical parameters, Report no. 37/11/2011, Oil and Gas Institute, Kraków, Poland (in Polish).

Zorski, T. (2009), Recent improvements in interpretation methodology applied in GeoWin SATUN application, AGH Geologia 35, 2/1, 549-557.

Zorski, T., A. Ossowski, J. Środoń, and T. Kawiak (2011), Evaluation of mineral composition and petrophysical parameters by the integration of core analysis data and wireline well log data: the Carpathian Foredeep case study, Clay Minerals 46, 1, 25-45, DOI: 10.1180/claymin.2011.046.1.25. 